\title{
ESTRUTURA E PRODUÇĀO DAS FLORESTAS NATURAIS AO LONGO DO RIO BRANCO NO TERRITÓRIO FEDERAL DE RORAIMA
}

Paulo Renato Schneider, Josē Alves da Silva e Franz H. Andrae Departamento de Ciências FLorestais. Centro de Ciências Rurais.UFSM. Santa Maria, RS.

Evandro Luiz Cozer

Curso de Engenharia Floresta 1. Centro de Ciências Rurais. UFSM. San ta Maria, RS.

RE SUMO

0 presente trabalho corresponde a uma sintese do inventā rio florestal realizado no Territōrio Federal de Roraima, no Norte do Paīs, na região de influēncia do Rio Branco, numa ārea de aproxi madamente 46.000 ha, pela Universidade Federal de Santa Maria.

Procurou-se descrever os tipos florestais encontrados na região sob o ponto de vista ecológico e de estoque de madeira, efe tuando-se considerações sobre o potencial das florestas, o processo e o estāgio de exploração em que se encontram e a vitalidade dos tron cos das diferentes espēcies encontradas.

SUMMARY

SCHNEIDER, P.R.; SILVA, J.A. da; ANDRAE, F.H. and COZER, E.L., 1982. Structure and yield of natural forests along the Branco River in the Federal Territory of Roraima (Brazil).Ciencia e Natura (4):115-127.

This paper is a summary of a forest inventory research pro ject carried out in North Brazil by the Universidade Federal de San ta Maria - RS, specifically, in the Federal Territory of Roraima, along the Branco River, comprising an area of aproximately 46.000 ha.

An attemp was made to describe all the forest types of the region from the ecological and timber stock points of view. Considerations about the current exploration process in the area and the trunk vitality of the various species were made.

INTRODUÇAOO

0 presente trabalho baseou-se no interesse particular do Governo do Territōrio em instalar um complexo hidrelētrico nas cor redeiras do rio Bem Querer, conforme relatōrio original*.

* Convênio: UNIVERSIDADE FEDERAL DE SANTA MARIA E gOVERNO DO TERRI TORIO FEDERAL DE RORAIMA. Inventārio florestal da āreăa de influência do Rio Branco entre as corredeiras do Bem Querer e Boa Vista - RR. Santa Maria, Imprensa Universi tāria da UFSM. 207 p. 
Neste caso, o conhecimento do potencial madeireiro estā di retamente relacionado com a possibilidade de uma posterior explora ção econômica das madeiras retiradas das áreas a serem inundadas. A exploração das essências florestais de maior valor econômico seria destinada à exportação, especialmente para a Venezuela, uma vez que a comercialização ou absorção destas madeiras pelo mercado nacional é, ainda, muito difícil. Os recursos advindos da comercialização se riam aplicados na construção da prōpria hidrelētrica.

Por outro lado, a energia produzida, no futuro, a lém de so lucionar o problema energético do Território, ainda dependente do óleo diesel, poderia ser utilizada pelas regiões vizinhas, especial mente no Estado do Amazonas.

\section{MATERIAL E METODOS}

\section{LOCALIZAĞO E CARACTERISTICAS DA AREA INVENTARIADA}

A ārea inventariada localiza-se na quadrícula geral,entre as coordenadas geogräficas: 10 50' e 20 50' de Latitude Norte e 60 o $30^{\prime}$ e 610 30' de Longitude Oeste e, especificamente, ao longo do Rio Branco em ambas as margens, incluindo-se ilhas, não ultrapassando a cota de inundação de 120 metros demarcada pelos Serviços Aerofotogra métricos Cruzeiro do Sul S/A.

A ārea delimitada pela cota de 120 metros abrange aproxi madamente $46.000 \mathrm{ha}$, incluindo extensas āreas do baixo Mucajaí, trí butário 0este e do Rio Cachorro, principal tributārio Leste.

0 início da área inventariada partiu das corredeiras do Bem Querer atē as cercanias da cidade de Boa Vista, em uma extensão aproximada de $110 \mathrm{~km}$.

o levantamento foi esquematizado partindo-se de um mapea mento básico feito através de triangulação radial mecânica, proces so dos moldes fissurados, com cinco pontos de apoio tomados em dis tribuição regular em imagens de radar obtidas pelo projeto Radam.

Posteriormente, efetuou-se a fotointerpretação preliminar demarcando-se a estratificação vegetal por porte e, depois, por den sidade, porte e diâmetro de copa em função de: textura fotogrāfica, tonalidade e micro relevo, usando-se 47 aerofotos de janeiro de 1978, em escala aproximada de 1:70.000.

A avaliação das āreas foi feita com correção do coeficien te de deslizamento do planímetro polar sobre poliester. A fotointer pretação das manchas florestais foi lançada sobre o mapa bāsico com o auxîlio da câmara clara.

CARACTERISTICAS AMBIENTAIS DAS FLORESTAS

A região de estudo pode ser considerada como uma transição 
entre zonas de floresta tropical pluvial da bacia amazónica es cha mados campos de Roraima, isto é, um complexo de campos e cerrados, que cobrem a parte setentrional do territōrio e as regiões adjacen tes na Venezuela e na Guiana.

A ārea prōxima à Boa Vista pertence a esta formação de cam pos cerrados, limitando as florestas a faixas, relativamente estrei tas que acompanham as margens dos cursos de āgua. A faixa de trans ção entre as formaçōes florestais e os campos cerrados é estreita e bastante brusca, sendo zonas de penetração mūtua das formações pra ticamente ausentes, lembrando, de certo modo, as mudanças bruscas na vegetação dos campos do planalto do Rio Grande do Sul, onde, tam bēm, existem formações de campos e de florestas (de Pinheiro bras $\underline{j}$ leiro), lado a lado.

As temperaturas são bastante uniformes o ano inteiro, cu jas médias mensais oscilam em torno de 27 graus. O critērio de difé renciação das estações do ano é a incidência de precipitações (cer ca de $1.750 \mathrm{~mm}$ anuais), dividindo o ano em duas estações: uma esta ção chuvosa, com maior intensidade de precipitação nos meses de maio e julho e uma estação seca, ocorrendo nos meses de dezembro a feve reiro.

A diminuição das chuvas durante o verão se reflete, conse quentemente, sobre a vegetação, fazendo com que as florestas sejam consideradas tropicais estacionais, apesar de sua proximidade geo grāfica com as florestas tropicais pluviais da bacia média do Amazo nas. Estas diferenças de vegetação se menifestam, porém, menos no sentido de terem aspectos e espēcies diferentes, porēm, mais com re lação aos períodos de desfolhamento das ārvores, e, possivelmente, no vigor das espēcies arbōreas e na exuberância das epífitas.

A maior parte das florestas inventariadas pode ser cons $i$ derada de florestas virgens, no que se refere à exploração flores tal. Aliās, isto ē facilmente compreensível, jā que até poucos anos não existia possibilidade de transportar madeira, senão através do prōprio Rio Branco.

\section{ASPECTOS ECOLOGICOS DOS TIPOS FLORESTAIS INVENTARIADOS}

Para efeito de cālculo volumētrico e anālise estatística dos resultados foram considerados três tipos florestais básicos: Flo resta de Igapó - Tipo Florestal 1, Florestas de Terra Firme - Tipo Florestal 2 e um terceiro Tipo Florestal formado pela reunião dos Tipos Campinarana, Chavascal e Restinga.

Os tipos de florestas invenfariados demonstram uma rela ção íntima com o regime hîdrico local, "em concordāncia com a litera tura sobre florestas tropicais e amazonicas, em especial, possibil $\underline{j}$ 
tando efetuar o agrupamento das florestas em floresta de Terra Fị me e de Igapó. As primeiras localizam-se fora da zona de alcance das cheias do Rio Branco, cujas āguas chegam a subir de 6 até 10 metros. $\mathrm{Na}$ Terra Firme encontra-se uma floresta fechada e alta, cujo estra to superior de copas está frequentemente rompido e ultrapassado por ārvores emergentes, alcançando cerca de 45 metros de altura e até mais de 2 metros de diāmetro. Os solos da região, geralmente, são arenosos e profundos com alguma matēria orgānica prōximo à superfí cie, sendo extremamente pobres.

0 segundo tipo de floresta ocorre nas āreas de inundação chamadas de Igapó, onde a àgua pode ficar estagnada durante um pe ríodo de 3 a 5 meses.

Há uma dependência do alagamento com o relevo que pode cau sar a estagnação da ägua durante períodos maiores ou facilitar um defiūvio rápido da āgua.

A estagnação è o principal fator responsável pela forma ção e caracterização das florestas que aí ocorrem, chegando a for mar verdadeiros povoamentos homogêneos, quando considerados, somen te, as espécies da camada superficial do estrato. Nestes casos ex tremos não se encontram espécies valiosas, e, as ārvores possuem for mas tortuosas, inclinadas, muito bifurcadas, ōcas e de tronco curto, sendo a altura destas florestas não superior a 15 metros.

Nos pontos onde o relevo è menos favorável à estagnação, ocorre uma maior riqueza de espécies, continuando porēm, o baixo va lor económico atual da floresta:

As partes mais ricas em madeiras, dentro do Igapō, são os "habitats" ondulados e as galerias ao longo do rio chamadas de Res tingas. A saturação do solo é bem menor, podendo ocorrer uma flores ta alta e diversificada.

o solo úmido do Igapó possibilita uma atividade extremamen te rápida e intensa da microvida. Deste modo, não há tempov sequer para a formação de camadas de folhas e outros detritos florestais junto à superfície do solo, tão rápida é a decomposição da matéria orgânica, garantindo um abastecimento iligeiro e contínuo com os nu trientes contidos nestes materiais. A atividade biológica no Igapó manifesta-se pela formação de verdadeiros camalhões de terra revira da e acumulada em torno do tronco das plantas. Estes camalhões for mam um elemento muito característico na superfïcie do solo do Igapó atingindo $20 \mathrm{~cm}$ de altura e um diâmetro de atē $60 \mathrm{~cm}$. Eles dificul tam, enormemente a locomoção, e, alēm disto, constituem um obstācu 10 sério para uma eventual exploração, face a sua ocorrência mac ça. 0 vigor das espēcies do Igapó é tanto mais reduzido, quanto mais pronunciada for a influēncia da àgua, sendo mais interessantes, do 
ponto de vista da produção florestal, aqueles locais, onde a água das inundações não fica parada, pois aî ocorre um maior nūmero de espé cies de valor econömico e as ārvores podem alcançar dimensões mais expressivas. Florestas do tipo Chavascal são semelhantes ao Igapó, porēm, ocorrem mais afastadas dos rios e as suas inundações são de vido à falta de escoamento das àguas de inverno. Trata-se de uma ve getação de porte entre Igapō e Campinarana com formações em touce $\underline{j}$ ras. O Chavascal ocorre sempre antes das formações de Terra Firme (são as baixadas prōximas à Terra Firme, com solo argiloso). Trata-se tambēm de uma floresta mais fechada e mais baixa que o Igapó.

\section{SISTEMA DE AMOSTRAGEM}

Levando-se em consideração as características da região ut lizou-se um sistema de amostragem aleatōrio estratificado. A popula ção florestal ( $31.891,65$ ha) foi estratificada por fotointerpretação em cinco tipos de vegetação características da região: Igapó com $25.883,20$ ha; Terra Firme: 441,00 ha; Campinarana: $1.832,00$ ha; Cha vasca 1: 2.241,75 ha; e Restinga: 1.493,10 ha. A distribuição das uni dades de amostra entre os estratos foi efetuada pela alocação propor cional ao tamanho dos estratos. Para efeito de cālculo da variāncia dos estratos e erro padrão da estimativa, preferiu-se reunir os es tratos Campinarana, Chavascal e Restinga em um ūnico grupo, em razão de suas dimensões.

Classificą̧ão e medição das árvores nas unidades de amostra

Em cada unidade amostral de 1,0 ha, em forma de cruz gre ga, foi coletado o conjunto de variāveis bāsicas destinadas à avalia ção dos diversos tipos florestais. Todas as ārvores-amostra com diâa metro a altura do peito superior ou igual a $25 \mathrm{~cm}$ foram enumeradas a partir do centro para a porção externa das sub-unidades. Cada är vore foi, posteriormente, identificada pelo seu nome vulgar, sendo o seu DAP medido. Além desta variāvel, mediu-se tambēm as alturas co merciais e totais, assim como a altura e largura das sapopemas. As informações coletadas foram anotadas em fichas especiais para poste rior computação.

\section{MEDICŨO DOS DIAMETROS EM NIVEIS SUPERIORES AO DAP}

Os diâmetros ao longo dos troncos foram medidos com 0 Re lascópio de Banda Larga, segundo o conceito de BITTERLICH $(1962,1964)$, atē a altura comercial.

Estas medições consistiram em dois pontos bāsicos: encon trar a altura de medição desejada no tronco e medir o seu diâmetro. Ambas as estimativas são efetuadas com medidas angulares, ou seja, 
valores relativos que deveriam ser transformados em valores absolu tos para efeito de cálculo dos volumes individuais. A distância hó rizontal do observador à ārvore selecionada foi medida com trena de fibra de vidro de 20 metros.

A determinação dos volumes comerciais individuais foi efe tuada pela fórmula de Smalian.

CLASSIFICAÇÃO DAS ARVORES QUANTO A POSIÇÃO SOCIOLOGICA E VITALIDADE

Para definir a posição sociológica das ārvores nos estra tos, utilizou-se a seguinte classificação: ārvores emergentes, domi nantes, dominadas e suprimidas. As classes de vitalidade foram def $\underline{i}$ nidas segundo a capacidade aparente de desenvolvimento que as ārvo res apresentavam nos diversos tipos florestais em "vigorosas", "nor mal", "pobre desenvolvimento" e "mortas".

\section{SELEÇ̃O DO MODELO DE QUAÇ̃O VOLUMETRICA}

Para a seleção do modelo de equação volumētrica utilizou-se o procedimento estatístico FORWARD, em vez de de desenvolver uma sé rie de modelos aritméticos, como apresentados em SPURR (1951), HUSCH et al. (1972) e LOETSCH et al. (1973).

As variāveis utilizadas para esta verificação foram consti tuỉdas por diferentes combinações de diāmetro e altura comercial na forma aritmética como: d, hc, dhc, $h^{2} \varepsilon, d^{2} h c^{2} e$, posteriormente na forma logarítmica.

Os volumes estimados foram corrigidos, aplicando-se a fōr mula de MEYER (1941), a fim de eliminar erros sistemáticos causados pela discrepāncia logarítmica.

Para verificar a independēncia dos residuos utilizou-se o Teste de Durbin-Watson, incluso no pacote SPSS, e, para a normalida de o Teste de Kolmogorov-Smirnov (SCHNEIDER, 1978).

\section{RESULTADOS E DISCUSSOES}

\section{SELEÇÃO DO MELHOR MODELO}

$\mathrm{Na}$ Tabela I foram sintetizadas as estatísticas obtidas pa ra a seleção da equação de regressão. As equações 1 e 2 apresenta ram-se como as equações-modelo possĩveis de serem usadas para a es timativa do volume com casca para o grupo de espécies amostradas.

A variāvel independente $d^{2} h$, na forma logarítmica, foi a - que apresentou maior correlação simples com o volume, sendo portan to, a variāvel selecionada no primeiro passo da regressão.

A inclusão da variāvel combinada (dh), na forma logarítmi ca, originou o modelo de equação 2 , aumentando a precisão das est 
mativas. Entretanto, qualquer um dos dois modelos poderão ser utili zados para as estimativas dos volumes sobre casca das espēcies estu dadas, principalmente, considerando-se que o aumento da precisão cau sado pela inclusão da nova variāvel não foi, consideravelmente, de grande magnitude.

Baseado nos resultados da Tabela I efetuou-se as estimati vas dos volumes individuais sobre casca, tomando-se a equação 2 co mo representativa dos dados. Esta equação da variāvel combinada na forma logarítmica deve ser usada para as alturas comerciais. 0 fator de correção foi igual a 1,0145113.

TABELA I. MODELOS DE REGRESSÃO PARA ESTIMATIVA VOLUMETRICA COM CASCA

\begin{tabular}{|c|c|c|c|c|c|c|c|}
\hline \multirow{2}{*}{ Eq. No } & \multirow{2}{*}{ REGRESSÃO } & \multicolumn{6}{|c|}{ ESTATISTICAS } \\
\hline & & Coeficientes & SxyB & R & $\mathrm{R}^{2}$ & Sxy & $\mathrm{F}$ \\
\hline \multirow[t]{2}{*}{1} & $\log V=b_{0}+b_{1} \log d^{2} h$ & $b_{0}-3,97675$ & & & & & \\
\hline & & $b_{1} \quad 0,92963$ & 0,00882 & 0,97720 & 0,95492 & 0,0737 & 11100,44 \\
\hline \multirow[t]{3}{*}{2} & $\log V=b_{0}+b_{1} \log d^{2} h+$ & $b_{0}-3,97327$ & & & & & \\
\hline & $+b_{2} \log d h$ & $b_{1} \quad 1,09541$ & & & & & \\
\hline & & $b_{2}-0,26963$ & 0,05727 & 0,97814 & 0,95676 & 0,0723 & 5785,49 \\
\hline
\end{tabular}

0 teste de Durbin-Watson indicou para os resĩduos estima dos pela equação 2 o valor de 1,68279 significativo ao nîvel de $5 \%$ de probabilidade.

Para o teste de normalidade encontrou-se $\mathrm{KS}=0,06596$ me nor que o valor de $1,63 \mathrm{~N}=0,07107$, ao nível de $1 \%$ de probabilidade.

\section{POSICAOO SOCIOLOGICA DAS ESPECIES POR TIPO FLORESTAL}

A porcentagem de ārvores dominadas e suprimidas, medidas dentro dos respectivos tipos florestais, foi relativamente baixa. Ve rificou-se que, em média, menos de $2,5 \%$ do volume medido em cada tị po florestal correspondiam às categorias de ārvores dominadas e su primidas. Em razão das caracterīsticas da ārea inventariada, o estra to formado pela Terra Firme podia ser considerado como zona de tran sição entre Igapó e a floresta alta.

Por este motivo, não se verificou uma presença marcante de ārvores emergentes, isto é, ārvores que sobressaíseem do estrato su perior, destacando-se das demais formas de vegetação. Poucas foram as espēcies observadas nestas condições, mesmo porque as ārvores das florestas tropicais se comportam muito diferentemente uma das outras quanto as suas necessidades de luz. Entre as espēcies que mais se destacavam dos estratos encontravam-se a Caferana (Dendrobangia bo Ziviana) em poucos exemplares, submetidas, atualmente, a um proce $\underline{s}$ so intenso de exploração na região. A Samauma (Seiba pentandra) foi observada, principalmente, em região de Igapō, às margens de rios ou 
nas Restingas, destacando-se de duas vizinhas especialmente pela for ma típica de suas copas. 0 Angelin da Mata (Hymenolobium excelsun), a Maçaranduba (Manilkara huberi) emergiam tambēm dos estratos, embora com baixa frequência. Nas partes mais baixas e úmidas, na ārea de in fluência dos igarapés, onde a estação seca não se fazia sentir tan to, ocorriam outras espécies, principalmente, a Manga Brava (Micropho lis guianensis), que aparecia em belos exemplares e grandes volumes por hectare. Entretanto, esta espécie não era apreciada na região, provavelmente devido à falta de informações sobre suas característị cas tecnológicas e possíveis usos.

Além da Manga Brava foram encontradas espécies de certo prestígio no mercado e que pareciam menos sensíveis às condiçóes de umidade permanente ou periódicas, demonstradas pelo seu aparecimen to em certos locais da floresta de inundação (igapō) como, por exem plo, Louros, Itaūba, Copaiba e Seringueiras.

Entre o conjunto de espēcies dominantes foram observadas a Copiuba (Goupa glabra), a Mangabarana (Micropholis guianensis), a Ucuuba (Virola sp.), os Taxis (Scherolobium paraensis) e outras.

No estrato inferior destacavam-se as Enviras, de vārias es pécies, as Abioranas (Pouteria spp.), os Ingās (Inga spp.), princí palmente, em terrenos inundāveis, o Mututi (Pterocarpus amazonicus ) tambēm, no igapó com alta frequēncia, a Muiratinga (Maquira sclerophylza), Faveiras e Itauba (Mezilaurus itauba) em menor frequēncia. No estra to inferior notou-se uma quantidade imensa de ārvores muito ramifi cadas e troncos curtos. (Veja Figura 1).

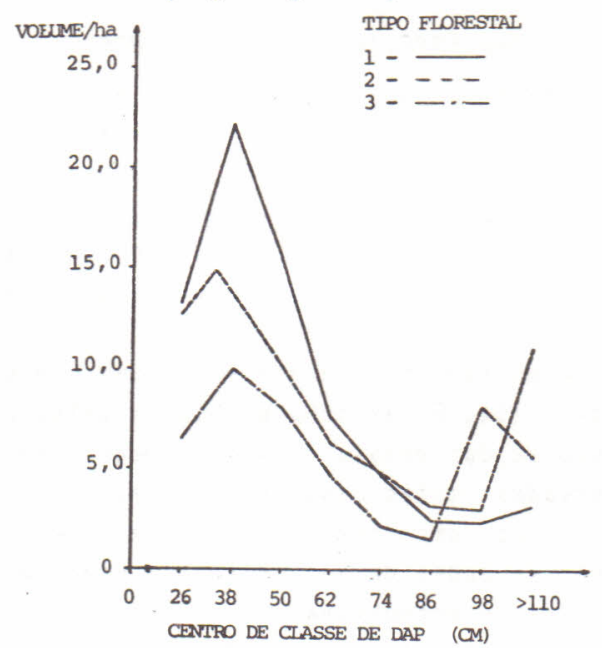

Figura 1. Volume com casca por classe de DAP (cm) e tipo florestal. 
Vitalidade das árvores por tipo florestal

Quanto à vitalidade das ārvores, independente da espēcie, observou-se que, em Terra Firme, cerca de $38 \%$ do nūmero de ārvores/ ha, ou seja, mais de $60 \%$ do volume total apresentavam um vigoroso de senvolvimento. Apenas cerca de $9 \%$ do volume total correspondiam à ärvores mortas, podres, etc.

No Igapó cerca de $45 \%$ do volume medido era composto por ār vores normais ou de vigoroso desenvolvimento. Arvores anormais como, por exemp 10, quebradas, ôcas, semi-apodrecidas etc. e mortas ocor riam em menor frequência (4 a 8 ārvores/ha, ou seja, cerca de $22 \%$ do total do número de ārvores por hectare).

No Tipo III, formado pela Campinarana, Chavascal e Restin ga cerca de $64 \%$ do volume total por hectare representavamärvores nor mais de vigoroso crescimento e $26 \%$ do nümero de ärvores correspon diam à ārvores mortas e defeituosas (Veja Figura 2). Em todos os Tí pos Florestais foram observados ärvores com DAP superior a 1,0 metro.

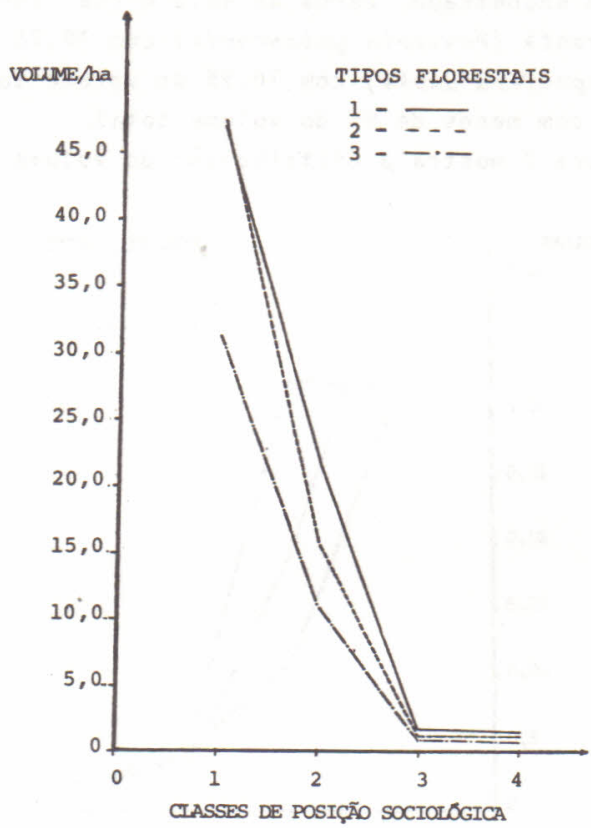

Figura 2. Volume com casca por classe de posição sociológica.

Verificou-se que o maior volume de madeira, independente da espécie, foi encontrado no Igapó, onde havia maior ocorrência de ärvores. Este tipo florestal contribuiu com cerca de $71,5 \mathrm{~m}^{3} / \mathrm{ha}$, ou 
seja, 38,8\% do volume total. Entretanto, $20,3 \%$ do volume total do Igapó, era constituido pelo Mututi da Vārzea com uma frequência de $46,5 \%$ ārvores/ha. Esta espécie possui apenas valor comercial em po tencial. Em segundo plano verificou-se que a Muiratinga contribuia com $16,98 \%$ do volume total do $\operatorname{Igapo}\left(12,15 \mathrm{~m}^{3} / \mathrm{ha}\right)$ com uma frequência de 17 ārvores/ha, seguida da Tapioqueira e do Arapari com menor con tribuição.

Em Terra Firme foi encontrado cerca de $66,3 \mathrm{~m}^{3} / \mathrm{ha}$, ou se ja, 36\% do volume total do Tipo. Entre as espēcies que mais contri buiram para a composição do volume total destacaram-se o Angelim da Mata com 9,75\% do volume total, Casca Grossa (Liriosma sp.) com 9,3\% do volume e a Mangabarana com 6,4\%.

A Mangabarana e a Casca Grossa representam o grupo de es pēcies potencialmente passíveis de serem exploradas, em razão daboa formação de seus fustes.

No tipo florestal III, formado pela Campinarana, Chavascal e Restinga foram encontrados cerca de $46,3 \mathrm{~m}^{3} / \mathrm{ha}$, constituido pelas espécies Abio Branca (Pouteria guianensis) com 16,7\% do volume to ta1, Copaiba (Copaifera ducke) com 10,9\% do volume total e Tapioquei ra e Muiratinga com menos de $9 \%$ do volume tota 1.

A Figura 3 mostra a distribuição do volume por Tipo Flo restal.

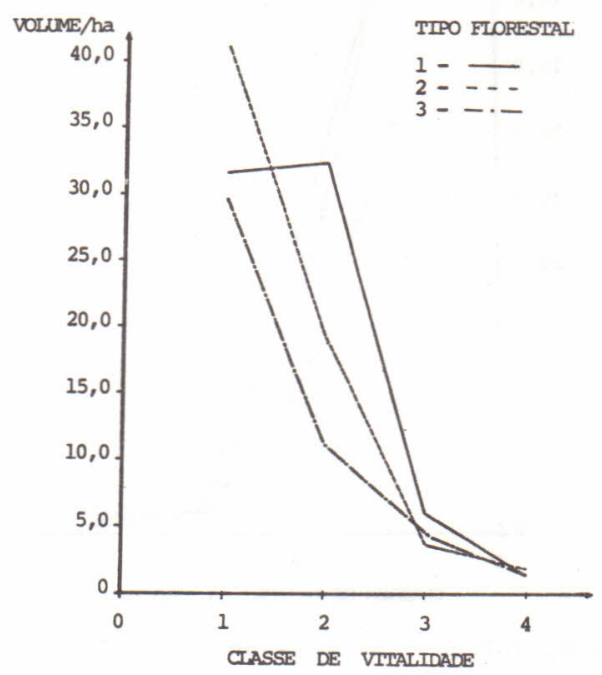

Figura 3. Volume com casca por classe de vitalidade.

ESTIMATIVAS DO INVENTARIO

A média estratificada estimada para a população foi de 
$67,07 \mathrm{~m}^{3} / \mathrm{ha}$ com casca.

A variāncia da média estratificada obtida foi de $12,65 \mathrm{~m}^{3} /$ ha, o que representa um erro de amostragem de 5,3\% em torno do volu me mēdio estratificado, atendendo plenamente a expectativa da preci são requerida na formulação dos objetivos do trabalho.

0 intervalo de confiança para o total da população foi de: IC $\left[1.891 .774 \mathrm{~m}^{3}<Y>2.386 .085 \mathrm{~m}^{3}\right]=95 \%$

\section{CONCLUSOES E RECOMENDAÇOES}

Para a estimativa dos volumes comerciais das espécies flo restais nas āreas de influência do Rio Branco, no Territōrio Federal de Roraima, verificou-se que os modelos de equações logarítmicas que envolviam a combinação das variāveis diāmetro e altura como variáveis independentes, obtidas pelo procedimento FORWARD, apresentaram as melhores estimativas volumētricas.

0 volume comercial com casca registrado neste inventário florestal foi extremamente baixo, sendo que, o Tipo Florestal Igapó possui $71,5 \mathrm{~m}^{3} / \mathrm{ha}$; o Tipo Florestal de Terra Firme $66,3 \mathrm{~m}^{3} / \mathrm{ha}$ e os Tipos FLorestais formados por Campinarana, Chavascal e Restinga 46,3 $m^{3} /$ ha.

Sob o ponto de vista ecolögico constatou-se que o potencial florestal da ārea concentra-se em um grupo de espēcies que não apre sentam um valor comercial expressivo.

observando-se o panorama dos tipos florestais e seus ambien tes, concluiu-se que o uso potencial destas florestas é bastante $1 \underline{i}$ mitado. Por um lado, pode-se-ia desenvolver a agricultura e pecuária somente em -areas de terra firme que, sob o ponto de vista flores ta1, ē, também, a mais interessante, pois possui espécies valiosas e um relevo sem maiores obstāculos para uma exploração ou manejo des tas florestas.

A maior parte da ārea inventariada possui solos extremamen te arenosos, sem reservas em nutrientes, muito sujeitas a erosão ace lerada quando retirada a floresta. Neste caso, pode-se sugerir somen te uma reconsideração urgente e radical dos programas de coloniza ção e extensão rural.

Nos moldes atuais de agricultura na região florestal de Ro raima pode-se prognosticar facilmente um declīnio rāpido da produtị vidade do solo e a necessidade de ocupar cada vez mais rāpido maió res äreas florestais para manter ou aumentar os nīveis de produção agrícola do Territōrio. Por outro lado, o sistema atual de explora ção florestal de Roraima que se desenvolve sem fiscalização local, num sistema de devastação sem escrúpulos, levando somente material 
de primeirissima qualidade para as serrarias, deixando enormes quan tidades de madeira apodrecer na floresta, somente por apresentar, aparentemente, certas falhas ou defeitos que, tecnicamente, não $1 \underline{i}$ mitariam sua aplicação. Devido à pequena frequência das espécies, atualmente cobiçadas pelo mercado externo, exploram-se áreas relatị vamente extensas, situadas naquelas regiões, com melhor infraestru tura.

As florestas de Igapó seriam bem mais problemáticas quan to ao uso florestal, sendo praticamente imprestáveis no que se refe re a uma ocupação agrícola. Os períodos longos de inundação exigem, automaticamente, um uso florestal exclusivo, com possibilidades de tornar-se economicamente viável na Restinga e em algumas partes adja centes à Restinga ou Terra Firme. Neste caso, elas são mais favorā veis a serem exploradas, uma vez que possuem boas condições de cul tivo de espécies valiosas.

o cultivo da Seringueira, poderia tornar-se uma alternati va interessante, visando à exploração do $1 a \bar{t}$ tex, dando ao extrativis mo do Territōrio uma nova opção. Boa parte dos Igapōs, aparentemen te, não têm condições de serem aproveitados atualmente, seja para fins agrícolas ou florestais, alēm de o povoamento natural ser de baixo valor econômico e a superfície do solo um grande obstáculo pa ra qualquer movimentação. Entretanto, tais condições naturais não tem constiuído obstáculo para a exploração florestal, especialmente, no Igapō. A exploração persiste, via de regra, usando-se as águas das cheias como suporte, a fim de penetrar na floresta, cada vez mais longe, atingindo as florestas de Terra Firme. A destruição das flo restas, aliada às transformações dos solos, causado pelo intemperis mo, e, aos residuos florestais abandonados tem causado o entulhamen to do leito dos rios, causando a diminuição de sua vazão, e, pior que isto, aumentando a área de penetração para a exploração irracio nal dos recursos florestais.

Devido à difícil penetração nas florestas de vārzea, de va lor relativamente limitado, ocorreram derrubadas naqueles pontos, on de a chamada terra firme, com suas espécies valiosas, quase alcançou as margens do rio.

Por outro lado, a construção da estrada que liga Boa Vis ta a Manaus, facilitou enormemente o acesso às florestas via terres tre. Na região do inventārio, esta estrada acompanha o curso do rio numa distância entre 4 a $10 \mathrm{~km}$, podendo-se observar uma devastação uniforme e total numa faixa de 500 a 1.000 metros de ambos os lados da estrada, onde colonos derrubam e queimam as florestas, a fim de fazer plantações pequenas de milho, mandioca (macaxeira), arroz, ba nana, transformando as lavouras, após o declínio rápido da produtí 
vidade, em pastagens.

Via de regra, o processo de desmatamento pode ser caracte rizado em duas fases: o uso das espécies comerciais com a finalida de de exportação de madeira serrada e a derrubada e queima da flores ta com a finalidade de transformar a mesma em uso agrícola ou pasto ril. Face a baixa densidade demográfica, este ūitimo processo ainda ocorre, porēm lentamente, uma vez que o INCRA parece ter o controle total sobre a colonização, não se registrando a instalação de gran des complexos de empresas agropecuārias.

Repete-se aî um fenōmeno observado em muitas outras regiões, onde a floresta desencadeou o desenvolvimento inicial, uma vez que fornecia lucro imediato. Entretanto, deve-se observar quanto maior for o grau de desenvolvimento alcançado, tanto mais necessitar-se-á da flo resta. Por isto, torna-se necessārio restringir a colonização em āreas edāficamente viāveis, deixando todos os outros solos que apre sentam maiores problemas de fertilidade e de conservação de sua su perfície com sua vegetação nativa. Deste modo, tornar-se-ia possível iniciar uma exploração florestal racional pela formação de unidades limitadas de florestas, como fazem os Estados Unidos, onde o lucro da exploração imediata é investido, total ou parcialmente, no melho ramento e enriquecimento das florestas nativas, a fim de tornar 0 seu uso economicamente rentāvel e duradouro para a Nação a médio prâ zo.

\section{REFERENCIAS BIBLIOGRAFICAS}

1. BitTERLICH, W. Relaskop mit Breitskala. A.F.z., Wien. 1962.

2 . - Stammkubierung mit denn Tele-Relaskop. Allgem

Forstzeitung, (6): 15 p. 1964.

3. HUSCH, B.; MILLER, C.I.; BEERS, T.W. Forest Mensuration. 2 ed. New York, Ronald Press. 410 p. 1972.

4. LOETSCH, F.; ZOEHRER, F. \& HALLER, K.E. Forest Inventory. Munchen. BLV Verlagsgesellschaft. 469 p., 2. v. 1973.

5. MEYER, H.A. A corretion for a systematic error occuring in the aplication of the logaritimic volume equation. Pensylvania Forest School Research. 3. p. 1941.

6. SPURR, S.H. Forest Inventory. New York, Ronald Press, 476 p. 1976.

7. SCHNEIDER, P.R. Modelos de Equações e Tabelas para Avaliar o Pe so de Casca de Acácia Negra (Acácia mearnsii de Wizd). Curitị ba. 149 p. (Tese Mestrado).

Recebido em setembro, 1982; aceito em outubro, 1982. 


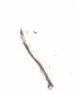

